\title{
O DEVIDO PROCESSO LEGAL E AS NULIDADES NO NOVO CÓDIGO DE PROCESSO CIVIL
}

\author{
The due process of law and the nullity in the new Code of Civil Procedure
}

\author{
Francisco José Rodrigues de Oliveira Neto
}

Resumo: O tema das nulidades processuais (ou "invalidades processuais", como alguns preferem), em tempos de excesso de processos em tramitação no Poder Judiciário e escassez de recursos materiais para fazer frente a tal demanda, aliado à natural e crescente complexidade das relações jurídicas, tem se mostrado como um dos mais instigantes nos últimos anos. A par da reconhecida dificuldade no seu enfrentamento, expressivos doutrinadores nacionais tem lançado uma série de ideias, as quais foram claramente adotadas pelo novo Código de Processo Civil (Lei n. 13.105, de 16 de março de 2015), o que justifica a reconstrução do pensamento de tais autores e os mecanismos oferecidos pelo legislador atual para o seu enfrentamento.

Palavras-chave: Devido processo legal. Processo civil. Nulidades processuais.

\begin{abstract}
The subject of procedural nullities (or "procedural irregularities", as some prefer), in a period of excess of processes pending in the judicial branch and shortage of material resources to cope with such demand, combined with increasing complexity of legal relations, has been one of the most instigating subjects in recent years. Aware of the recognized difficulty in coping with procedural nullities, expressive Brazilian scholars have released a number of ideas that were clearly adopted by the new Code of Civil Procedure (Law no. 13105, 16 March 2015), justifying the reconstruction of thinking of such authors and the mechanisms offered by the current legislators for solving them.
\end{abstract}

Keywords: Due process. Civil procedure. Procedural nullities.

Artigo recebido em 23 jun. 2019 e aprovado em 26 ago. 2019. 


\section{Introdução}

De início, é importante destacar as palavras do Prof. Egas Dirceu Muniz de Aragão, quando diz que "É este um dos mais árduos capítulos do Código. Tanto faz que seja encarado por um ou por outro de seus ângulos, as dificuldades são grandes e pouco variam. Complexo tanto para o legislador, que tem que elaborá-lo, quanto para o magistrado, que tem que aplicá-lo. Também é penoso igualmente para uma das partes, que vê perdido o seu esforço, quanto para a outra, que poderá sofrer os efeitos de um ato indevido". Mais adiante, completa: "Ninguém lhe atravessa os umbrais sem receios" (ARAGÃO, 2004).

Tais palavras bem refletem o sentimento de todos que se deparam com o trato das nulidades (ou invalidades) processuais, em especial, quando diante de uma situação concreta em determinado processo: ao se constatar a existência de um defeito na formação do ato, a primeira tentativa é de superação, mas - por vezes - isso se mostra impossível e o reconhecimento da falha se torna necessário, fazendo cair por terra tempo e dedicação, prolongando um litígio e retardando a tão desejada pacificação social, objetivo maior do processo e da atuação do Estado no exercício da função jurisdicional ${ }^{1}$.

E é justamente essa inquietação, esse desconforto, que justifica tratar das nulidades processuais no novo Código de Processo Civil (Lei n. 13.105, de 16 de março de 2015), já que a nova legislação - em que pese possa parecer, a uma primeira vista (apenas parecer), apresentar poucas alterações, justifica um olhar mais atento em relação a tema tão instigante e tão complexo.

Retroagindo no tempo, percebe-se que, no Código de Processo Civil de 1939, a matéria foi tratada de modo inovador em relação ao sistema anterior, que era o chamado Regulamento 737, de 25 de novembro de 1850, considerado - nas palavras de Pedro Miranda de Oliveira - o primeiro instituto processual puramente brasileiro (OLIVEIRA, 2016, p. 29). Naquele

\footnotetext{
${ }^{1}$ Tanto é assim que, no art. 12, NCPC, foi inserida regra com o objetivo de minimizar o atraso que porventura venha a ocorrer: "Os juízes e os tribunais atenderão, preferencialmente, à ordem cronológica de conclusão para proferir sentença ou acórdão. \ $0^{\circ}$ Ocupará o primeiro lugar na lista prevista no $\int 1^{\circ}$ ou, conforme o caso, no $\int 3^{\circ}$, o processo que: I - tiver sua sentença ou acórdão anulado, salvo quando houver necessidade de realização de diligência ou de complementação da instrução".
} 
conjunto normativo, havia uma descrição das nulidades que poderiam contaminar o ato processual, o que foi abandonado no CPC de 1939 e também no CPC de 1973.

O CPC de 2015 segue a mesma linha, mas inova - apesar de alterar fundamentalmente questões gramaticais -, na medida em que abre espaço para uma participação mais efetiva e concreta das partes na condução do feito. A corresponsabilidade, vista a partir de institutos como o negócio jurídico processual com a flexibilização de regras procedimentais e ampliação do contraditório, faz com que as nulidades processuais passem a ser examinadas com uma perspectiva mais ampla e com foco na finalidade do processo, não perdendo de vista o respeito ao devido processo legal.

Eis a pretensão deste estudo: descrever as teses que foram construídas a partir dos nossos modelos legislativos até o sistema de enfrentamento das nulidades adotado no CPC de 2015, destacando suas particularidades e possibilidades no contexto da lógica atual do processo civil.

\section{O devido processo legal e sua relação com as nulidades}

Como bem recorda Cândido Rangel Dinamarco, “as exigências formais do processo não passam de técnicas destinadas a impedir abusos e conferir certeza aos litigantes" (DINAMARCO, 2009, p. 615), tudo como evidente manifestação da cláusula do devido processo legal, até porque as nulidades têm por consequência um desequilíbrio na relação processual. É a busca do processo justo, com a compreensão de que, a violação de regras formais poderá comprometer o resultado final.

Para explicar essa relação, por mais evidente que seja, pensamos ser adequado resgatar a lição de dois dos maiores pensadores da teoria do direito: Hans Kelsen e Luigi Ferrajoli.

O primeiro, em sua Teoria Pura do Direito, ao tratar do direito material e do direito formal, destaca o que chama de "conexão sistemática", e assim a explica:

As normas gerais criadas por via legislativa (como leis ou decretos) ou por via consuetudinária devem ser aplicadas pelos órgãos para tal competentes, os tribunais e as autoridades administrativas. Estes órgãos aplicadores do Direito têm de ser determinados pela ordem jurídica, quer dizer: é necessário que se determine sob que condições 
um determinado individuo funciona como juiz ou autoridade administrativa. É, porém, necessário determinar também o processo pelo qual deve ser exercida a sua função, isto é, a aplicação de normas gerais. (KELSEN, 1998, p. 256)

Há então uma dupla função da norma jurídica: de um lado determinar o processo a ser observado e, de outro, o conteúdo a ser aplicado na construção da "norma individual". Demonstra que tais funções são inseparáveis.

Já Luigi Ferrajoli, em Principia Juris, apresenta-nos um raciocínio cujo ponto de partida é a distinção entre democracia formal e democracia substancial. Neste, a primeira cuida do "quem" e do "como", ou seja, das formas e dos procedimentos idôneos para garantir que as decisões sejam expressões da vontade popular, ao passo que a segunda (democracia substancial) se debruça sobre o "que", vale dizer, o conteúdo, considerando-se que, a seu ver, a concepção meramente formal da democracia não é suficiente (FERRAJOLI, 2011, vol. 2, p. 09).

Aqui, da mesma forma que na obra de Hans Kelsen, percebe-se que o aspecto formal e o aspecto material são indissociáveis. São duas faces da mesma moeda, não só da democracia, mas também de todo o direito positivo, não se podendo abrir mão de um sem que o outro seja afetado, podendo até mesmo comprometido.

Seja na teoria política, seja na teoria do direito, a dualidade entre forma e conteúdo sempre estará presente, assim como sua inseparabilidade, a tal ponto de, em determinados momentos, a própria norma de conteúdo formal assumir, quando violada, um aspecto material. No dizer de FERRAJOLI (2011, vol. 2, p. 30) opera-se uma metamorfose em que as normas formais aparecem destacadas como normas substanciais sobre a produção das decisões que são ditadas justamente sobre sua violação. Revela-se, então, um aspecto material (substancial) na norma até então apresentada unicamente como formal.

Assim, vencidas essas questões de ordem mais geral, as quais mostram a indispensabilidade de atenção à forma de modo indissociável da substância, é o momento de examinar o ato processual em si e sua relação com as invalidades. 


\section{Os atos processuais (atos jurídicos)}

Como afirma ARAKEM DE ASSIS (2015, p.1619), os fatos (os eventos e as condutas) interessam ao direito caso exista a previsão na norma jurídica. O suporte fático e seu ingresso no mundo jurídico pressupõem o atendimento de certos elementos de modo que, se houver o preenchimento suficiente destes, o fato jurídico será existente.

A questão relacionada ao modo como tais elementos forem atendidos é o que diz respeito à sua validade (ou plano da validade), "no qual o direito realiza a triagem entre os atos válidos e os atos inválidos ou não válidos. Já os eventos ficam confinados ao plano da existência. Eles jamais passam ao plano da validade, porque este envolve o elemento cerne do suporte fático - a vontade humana" (ARAKEM DE ASSIS, 2015, p. 1619).

Daí ser possível afirmar que três são os planos de projeção que podem ser atingidos pelos atos processuais (atos jurídicos): o da existência, o da validade e o dos seus efeitos (eficácia), sendo que o último pressupõe o segundo e este, evidentemente, pressupõe o primeiro. Algo como: existência - validade - eficácia, em que a eficácia pressupõe a validade, que pressupõe a existência. Isso se dá porque o processo também se insere na categoria maior ato jurídico e, assim, igualmente, submete-se aos requisitos gerais de todos os atos jurídicos, a saber: capacidade dos agentes, licitude do objeto e forma prescrita ou não defesa em lei.

Os dois primeiros requisitos não se incluem unicamente no campo das nulidades, posto que o primeiro é elemento da formação da relação processual, ao passo que o segundo é relacionado ao objeto, do que cuidam, por exemplo, os arts. 139, III, e 142, NCPC $^{2}$.

Levando em conta o caso da capacidade dos agentes, há incidência das regras do direito civil que se refletem na formação da relação processual: maioridade, representação, assistência e capacidade postulatória.

Sem dúvida alguma, porém, é em relação ao terceiro dos elementos apontados como essenciais de todos os atos jurídicos (forma prescrita

\footnotetext{
2 Art. 139. O juiz dirigirá o processo conforme as disposições deste Código, incumbindo-lhe: III - prevenir ou reprimir qualquer ato contrário à dignidade da justiça e indeferir postulações meramente protelatórias. Art. 142. Convencendo-se, pelas circunstâncias, de que autor e réu se serviram do processo para praticar ato simulado ou conseguir fim vedado por lei, o juiz proferirá decisão que impeça os objetivos das partes, aplicando, de ofício, as penalidades da litigância de má-fé.
} 
ou não proibida por lei) o momento em que se manifestam de modo mais intenso as invalidades processuais, já que dizem respeito àquilo que é sua essência, ou seja, a forma (o modo) como são praticadas.

Retomando os três planos do ato jurídico ou do ato processual, é que constamos que a inexistência efetivamente fica fora do regime das invalidades, já que, se um ato não existe, não há o que se reconhecer em termos de invalidades.

Nas palavras de Pontes de Miranda: "O que não foi feito não existe e, pois, não pode ter defeito” (PONTES DE MIRANDA, 1973, p. 42). É o não ato, existe no mundo dos fatos, mas não existe no mundo do direito (júri sumulado, audiência simulada).

Situa-se em plano anterior ao campo das invalidades e mereceu atenção do legislador processual em alguns momentos, como se pode ver pela classificação dos chamados "pressupostos processuais", os quais podem ser de existência (jurisdição e capacidade de ser parte) ou de validade da relação processual (inexistência de fatos impeditivos da relação processual - coisa julgada, litispendência, etc.; normas de procedimento; capacidade de estar em juízo; capacidade postulatória; competência; e imparcialidade).

Assim, não há como afirmar que as inexistências são irrelevantes para o processo civil. É o que se vê de algumas previsões como, por exemplo, o art. 525, parágrafo 1ㅜ inciso I, $\mathrm{NCPC}^{3}$, que prevê uma hipótese de ausência do ato que importará em considerar como "não ato" todo o processo a partir de quando tal deveria ter ocorrido.

Vencido isso, mais uma vez buscamos em Pontes de Miranda o rumo a ser seguido no trato da matéria, vencida a questão das inexistências: "Defeito não é falta. O que falta não foi feito. O que foi feito, mas tem defeito, existe. O que não foi feito não existe, e, pois, não pode ter defeito".

Em dado momento, o mesmo autor afirma: "dizer que o legislador pode destruir a separação entre inexistência e nulidade é o mesmo que supô-lo apto a, por exemplo, decretar mudança de sexo ou abrir audiência na lua" (PONTES DE MIRANDA, 1973, p. 353).

\footnotetext{
${ }^{3}$ Art. 525. Transcorrido o prazo previsto no art. 523 sem o pagamento voluntário, inicia-se o prazo de 15 (quinze) dias para que o executado, independentemente de penhora ou nova intimação, apresente, nos próprios autos, sua impugnação. \1º $\mathrm{Na}$ impugnação, o executado poderá alegar: I - falta ou nulidade da citação se, na fase de conhecimento, o processo correu à revelia;
} 
É bem verdade que os exemplos já foram superados, mas a distinção entre inexistência e nulidade ainda não. Tanto que o legislador atual corrigiu uma imperfeição do CPC/73. Seu art. 37 estava assim redigido:

Sem instrumento de mandato, o advogado não será admitido a procurar em juízo. Poderá, todavia, em nome da parte, intentar ação, a fim de evitar decadência ou prescrição, bem como intervir, no processo, para praticar atos reputados urgentes. Nestes casos, o advogado se obrigará, independentemente de caução, a exibir o instrumento de mandato no prazo de 15 (quinze) dias, prorrogável até outros 15 (quinze), por despacho do juiz. Parágrafo único. Os atos, não ratificados no prazo, serão havidos por inexistentes, respondendo o advogado por despesas e perdas e danos.

No NCPC, a matéria é tratada no art. 104, onde está dito:

O advogado não será admitido a postular em juízo sem procuração, salvo para evitar preclusão, decadência ou prescrição, ou para praticar ato considerado urgente. \19 Nas hipóteses previstas no caput, o advogado deverá, independentemente de caução, exibir a procuração no prazo de 15 (quinze) dias, prorrogável por igual período por despacho do juiz. $\int 2^{\circ} \mathrm{O}$ ato não ratificado será considerado ineficaz relativamente àquele em cujo nome foi praticado, respondendo o advogado pelas despesas e por perdas e danos.

Ocorreu, percebe-se, a substituição da palavra "inexistentes" por "ineficaz", o que é o correto por dois motivos fundamentais: 1) porque ali não há ausência de capacidade postulatória, mas sim impossibilidade de que ela produza seus efeitos naquele processo já que está submetida a uma condição de eficácia: a sua apresentação na forma e no prazo legal; e 2) porque assim é que está colocado no art. 662, do Código Civil: “Os atos praticados por quem não tenha mandato, ou o tenha sem poderes suficientes, são ineficazes em relação àquele em cujo nome foram praticados, salvo se este os ratificar".

Com isso, mais claro fica o espaço de análise das nulidades: é o que foi feito, mas tem defeito.

\section{As nulidades processuais: tipologia}

De início, duas observações. 
A primeira é a de que, analisada a legislação a respeito no CPC/2015 (arts. 274 a 281, em especial), tem-se a mesma impressão retratada por Pontes de Miranda quando analisa o assunto e destaca que a preocupação do legislador foi maior com regras jurídicas contrárias às nulidades ou à sua decretação: "O legislador traduziu bem o seu propósito político de salvar os processos. A vida a roer os restos do medievalismo...” (PONTES DE MIRANDA, 1973, p. 353). Permanece entre nós a lógica de que o sistema é feito para que não ocorram invalidades, de modo que sempre haverá a intenção de "salvar" o ato.

A segunda é a de que há uma divergência estabelecida em relação à palavra utilizada para retratar o fenômeno: muitos apontam que a palavra "nulidade" é inadequada, posto que nulidade é o vício, é o defeito, ao passo que "invalidade" (a mais adequada) aponta o que resulta da desconstituição do ato e dos seus efeitos, além de ser o contrário de válido. O legislador utilizou - a exemplo dos códigos anteriores - a palavra nulidades.

Dito isso, é preciso ainda observar que não se pode desconhecer que as nulidades não são tratadas apenas no direito processual, havendo quem aponte semelhanças com as nulidades do direito civil, e disso decorrem consequências importantes. A começar pelo detalhe de que o conceito oferecido pelos estudiosos das nulidades do direito civil tem origem no direito privado, ao passo que o processo civil é ramo do direito público, o que explica a importante conclusão de que não há invalidade processual de pleno direito. Todas precisam ser decretadas, isso porque "A relação entre Estado e indivíduo, exercendo aquele o poder e estando este em estado de sujeição, impede que a pessoa faça seu próprio juízo sobre a regularidade do ato e conclua por mostrar-se indiferente a ele" (DINAMARCO, 2009, p. 605).

Desta forma, pode-se afirmar que, ao contrário do que ocorre em direito civil, o ato processual produz efeitos até a decretação de sua invalidade já que, repito, não há invalidade (nulidade) de pleno direito. Todas precisam ser decretadas.

Quanto aos tipos de nulidades, antes mesmo do CPC de 1973, três importantes autores apresentaram teorias delineando o tema das nulidades no processo civil brasileiro, todos com a intenção de sistematizar sua compreensão: Pontes de Miranda, Galeno Lacerda e J. J. Calmon de Passos. 
Usando as palavras de Egas Dirceu Moniz de Aragão, foi Galeno Lacerda, em 1953, na obra intitulada Despacho Saneador, quem desvendou o sistema adotado pela lei à época vigente, identificando quatro pontos fundamentais no trato da questão: finalidade, conversão, prejuízo e repressão ao dolo processual. Com isso, no compreender de Egas, surgia a possibilidade de abandonar-se o subjetivismo que até então imperava no trato da matéria, o que entendia como possível extrair da classificação apresentada por J. J. Calmon de Passos que, em lado oposto, sustentava que todo o capítulo das nulidades deveria estar subordinado aos "fins de justiça do processo" (ARAGÃO, 2004, p. 289).

Aqui surge uma primeira classificação com larga utilização entre a doutrina: inexistências, nulidades absolutas, nulidades relativas, anulabilidades e meras irregularidades, que emprega de modo muito claro dois critérios: a natureza da norma violada (cogente ou dispositiva) e o interesse tutelado (público ou privado).

Vencida a primeira categoria (inexistência) - e que já foi objeto de exame -, as nulidades absolutas seriam aquelas em que há um vício mais grave (norma cogente), prevalecendo o interesse público a respeito do qual as partes não têm qualquer poder de disposição e que deve ser declarada de

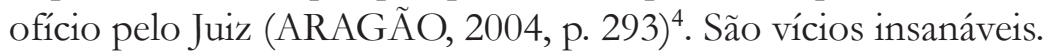

Já as nulidades relativas são aquelas em que a norma violada diz respeito ao interesse da parte, sendo o vício do ato sanável. Necessita que a violação seja de norma cogente e o juiz esteja autorizado a, de ofício, determinar a correção do ato (GALENO, 1953).

Ao contrário da absoluta, em que o vício não pode ser corrigido pelo juiz, que se limita a decretar sua ocorrência, na relativa há possibilidade de sanar de ofício mesmo que as partes nada tenham dito ${ }^{5}$. Ou seja, são sanáveis.

Quanto às anulabilidades, há uma violação de norma dispositiva (que são raras no processo civil), de modo que o ato fica na esfera de dis-

\footnotetext{
${ }^{4}$ Exemplos no NCPC: falta de fundamentação adequada (art. 489, par. 1ํ); sentença extra petita (art. 492); falta de título adequado (art. 803, I); cerceamento de defesa; violação de competência absoluta; reconhecimento de falta de pressuposto processual (art. 485, par. 3ํㅡㄴ inciso IV).

${ }^{5}$ Exemplos no NCPC: constrição de bens absolutamente impenhoráveis (art. 833); defeito de representação (art. 76); citação em período de gala (art. 244, III, a qual poderá ser suprida na forma do art. 239, par. $\left.1^{\circ}\right)$.
}

Resenha Eleitoral (Florianópolis), v. 22, n. 1-2, p. 35-50, 2018 
posição da parte e sua anulação somente poderá ocorrer mediante a reação do interessado, vedada a atuação de ofício do juiz ${ }^{6}$.

Por fim, as meras irregularidades, que são aquelas cuja violação da norma processual não gera qualquer consequência. São defeitos mínimos (não usar vestes talares durante a sessão de julgamento, numeração equivocada da fls. do processo, art. 208, NCPC; descumprimento dos prazos do art. 226, NCPC; erro material da sentença - art. 494, I, NCPC).

Seguindo essa classificação, temos autores como E. D. Moniz de Aragão e Araken de Assis. Divergindo, autores como Humberto Theodoro Júnior e Cândido Rangel Dinamarco, cabendo a este último explicitar o motivo da discordância: a impossibilidade de aceitação da anulabilidade em direito processual civil.

Diz ele:

A concepção publicista dos atos do Poder Judiciário e da técnica que conduz à sua anulação quando defeituosos exclui os conceitos de anulabilidade do ato processual e de ato processual anulável. Tais categorias são próprias do direito privado, que contempla duas espécies centrais de defeitos dos negócios jurídicos, a saber: a) os vícios radicais, que impedem desde logo a produção dos efeitos programados pelos agentes e caracterizam as nulidades de pleno direito, ou pleno jure; b) os vícios menos graves, que não impedem a produção de efeitos, mas deixam à parte inocente o direito potestativo de postular em juízo a subtração destes, pela técnica das anulabilidades e da anulação" (DINAMARCO, 2009, p. 607).

Mais à frente, é enfático: "muito diferentemente se dá em direito privado, o nulo processual depende sempre de anulação, quer se trate de nulidade absoluta ou relativa" (DINAMARCO, 2009, p. 608).

Em face disso, tais autores sustentam uma classificação em que temos: inexistências, nulidades absolutas, nulidades relativas (normas de interesse da parte, não conhecíveis de ofício e que devem ser arguidas na primeira oportunidade de manifestação) e meras irregularidades.

A par das anteriormente colocadas, há mais uma classificação que merece registro.

\footnotetext{
${ }^{6}$ Exemplos no NCPC: impenhorabilidade relativa (art. 834); ordem de ouvida na audiência (art. 361); falta de alegação de convenção de arbitragem (art. 337, par. $6^{\circ}$ ); violação do art. 486, par. $2^{\circ}$, e o réu nada diz.
} 
Fredie Didier Jr. adota classificação que, diz ele, decorre da compreensão de somente há uma categoria que importa, que é a das invalidades processuais, sendo que a distinção deve ser feita é a partir não dos tipos de invalidades, mas sim dos tipos de defeito processual.

Para ele, temos:

1) Defeitos processuais que não geram qualquer invalidade: são os defeitos mínimos chamados por muitos como meras irregularidades (não usar a toga durante a sessão de julgamento no Tribunal). São as irregularidades.

2) Defeitos processuais que geram invalidade que não pode ser decretada de ofício: são aquelas que tutelam interesses particulares, devem ser requeridas pela parte na primeira oportunidade em que lhe cabem falar nos autos e, se não o fizer, dá-se a preclusão (exemplo: art. 337, parágrafo 6ํㅡ, NCPC). São as anulabilidades.

3) Defeitos processuais que podem ser decretados de ofício: é o caso de invalidades que decorrem de desrespeito às normas de procedimento. Não há preclusão. São as nulidades absolutas.

4) Defeitos processuais que apresentam invalidades que podem ser decretadas de ofício mas, se a parte nada disse na primeira oportunidade, há preclusão (caso da citação defeituosa, mas há a apresentação da resposta ou, ainda, do foro de eleição, mas não arguido pela parte). São as nulidades relativas.

\section{Considerações finais: o tratamento da matéria no novo Código de Processo Civil}

A primeira observação que merece ser feita, diz respeito à distinção entre nulidades cominadas (expressas) e não cominadas (implícitas).

No art. 276, NCPC, onde está dito que "Quando a lei prescrever determinada forma sob pena de nulidade, a decretação desta não pode ser requerida pela parte que lhe deu causa", são descritas as nulidades cominadas que tem como exemplos os arts. 279 e 280, estando ainda presentes em diversos momentos do NCPC: arts. 11, 146, par. 7ㅇ 190, par. único, 239, par. $1^{\circ}, 272$, par. $2^{\circ}, 5^{\circ}, 8^{\circ}$ e $9^{\circ}, 525$, par. $1^{\circ}$, inciso I, 803, par. único, 1013 , II e IV; 64, par. 4ㅜㅇ 803 , e outros. 
Já as não cominadas são aquelas em que a nulidade é desprovida de expressa estipulação nesse sentido. É o que decorre do art. 277, NCPC, no qual está dito que "Quando a lei prescrever determinada forma, o juiz considerará válido o ato se, realizado de outro modo, lhe alcançar a finalidade".

Frente a isso, a questão que se coloca é: há compatibilidade entre essa classificação (nulidades cominadas e não cominadas) e as classificações anteriores (nulidade absoluta, nulidade relativa e anulabilidade)?

É um questionamento que leva a incertezas, já que o fato de se tratar de nulidade absoluta não importa em classificá-la como nulidade cominada, o mesmo valendo para a nulidade relativa e a nulidade não cominada. Afinal, a invalidade somente será inevitável quando, além de cominada, for absoluta, e mais por ser absoluta do que por ser cominada. E seguindo em tal raciocínio, é possível afirmar que podemos ter nulidades absolutas cominadas, nulidades absolutas não cominadas, relativas cominadas e relativas não cominadas.

Para alguns autores, o que de fato acontece é que a separação entre nulidades cominadas e não cominadas é uma classificação que remete ao já mencionado Regulamento 737 de 1850, permanecendo de modo inadequado em nosso sistema processual.

Naquela legislação, o art. 672 dizia que eram nulos os processos "I 1 Sendo as partes ou algumas dellas incompetentes e não legitimas como o falso, e não bastante procurador, a mulher não commerciante sem outorga do marido, o menor ou pessoas semeIhantes sem tutor ou curador. $\int 2^{\circ}$ Faltando-Ihes alguma fórma ou termo essencial. $\int 3^{\circ}$ Preterindo-se alguma fórma que o Codigo exige com pena de nullidade".

No artigo seguinte, descrevia quais eram as "formulas, e termos essenciaes do processo": a conciliação, a primeira citação pessoal na causa principal e na execução, a contestação, a dilação das provas, a sentença, a publicação da sentença, a exibição inicial dos instrumentos do contrato, nos casos em que o Código a considera essencial para a admissão da ação em Juízo, a citação da mulher quando a ação ou a execução versam sobre bens de raiz, a penhora, etc.

E na sequência afirmava: 
Art. 674. As referidas nullidades podem ser allegadas em qualquer tempo e instancia; annullam o processo desde o termo em que se ellas deram quanto aos actos relativos, dependentes e consequentes; não podem ser suppridas pelo Juiz, mas sómente ratificadas pelas partes.

Art. 675. As demais formulas não referidas no art. 673 se haverão por suppridas si as partes as não arguirem, quando, depois que ellas occorrerem, lhes competir o direito de contestar (art. 97), allegar afinal (art. 226), ou embargar na execução (arts. 575 e 576).

Contudo, o que ocorreu é que, nos Códigos subsequentes, a técnica de elencar quais eram as nulidades foi abandonada, optando-se critério diverso, tanto que a cominação não foi um critério levado em consideração, nem por Galeno Lacerda e muito menos por J. J. Calmon de Passos. Quem os levou em consideração foi Pontes de Miranda, dizendo ele que

No sistema jurídico do Código de Processo Civil de 1973, tal como antes, há distinção que está à base mesma da sua teoria das nulidades: nulidades cominadas, isto é, nulidades derivadas da incidência de regra jurídica em que se disse, explicitamente, que, ocorrendo a infração da regra jurídica processual, a sanção seria a nulidade; nulidades não cominadas, isto é, nulidades que resultam da infração de regras jurídicas processuais, mas para as quais não se disse, explicitamente, que a sanção seria a nulidade”. (PONTES DE MIRANDA, 2001, p. 355)

Com os demais, chegou-se à conclusão de que é impossível ao legislador prever todas as formas possíveis e imagináveis de violação da norma jurídica. Além disso, é preciso deixar alguma margem de liberdade para adaptação de novas e melhores formulações que possam (e que, efetivamente, surgem, com o passar dos anos) aprimorar a técnica processual.

No dizer de C. R. Dinamarco:

Racionalmente, o legislador toma consciência de sua própria falibilidade e, renunciando à utópica aspiração a um numerus clausus completo e sem omissões, resigna-se a especificar apenas algumas hipóteses em que o ato será nulo e, no mais, deixa ao intérprete a avaliação da aptidão de cada um deles a produzir o escopo para o qual foi concebido" (DINAMARCO, 2009, p. 610). 
E é justamente por isso que a manutenção deste modelo no CPC/2015 tem merecido críticas, apesar do reconhecimento do acerto da supressão da expressão "sem cominação de nulidade" no art. 277, que substituiu o art. 244, CPC/73.

Agora, adotada qualquer das classificações apresentadas, em que pese entender que as razões de C. R. Dinamarco para excluir as anulabilidades é de grande sentido, mostra-se preciso delimitar o campo de aplicação dos dispositivos que tratam do assunto no NCPC:

1) $O$ art. 276 claramente só tem aplicação para as chamadas nulidades relativas, não havendo qualquer sentido em estender sua aplicação para as nulidades absolutas, já que elas podem ser suscitadas a qualquer tempo e devem ser conhecidas de ofício pelo Juiz. Adotada a classificação de Galeno Lacerda, tem aplicação apenas para as hipóteses de anulabilidades.

2) $\mathrm{O}$ art. 277, que trata do princípio da instrumentalidade das formas (se alcançada a finalidade, tem-se por superada a nulidade), é norma que tem aplicação tanto para as nulidades absolutas quanto para as nulidades relativas. No caso da primeira, em que pese haver uma presunção de prejuízo, não há caráter absoluto e, se demonstrado o contrário, superada estará a questão. Na classificação de Galeno Lacerda, tal mereceria aplicação apenas nas nulidades relativas e nas anulabilidades.

3) $O$ art. 278 não deixa dúvidas: o caput serve às nulidades relativas (e anulabilidades, para Galeno), e o parágrafo único, às nulidades absolutas.

4) $O$ art. 279 apresenta uma regra de nulidade absoluta, que foi mitigada com o parágrafo $2^{\circ}$. Vale dizer que este incide o princípio da instrumentalidade das formas de modo a impedir a invalidação do processo, se não houver prejuízo.

5) O mesmo ocorre com as citações e as intimações previstas no art. 280, NCPC.

6) Por fim, o art. 282: apesar das divergências, tem-se como majoritária a compreensão de que se aplicam tanto as nulidades absolutas como às nulidades relativas.

Assim, em conclusão, é preciso destacar que - apesar do reconhecimento da importância da forma e do respeito ao devido processo legal - a intenção do legislador foi seguir os passos da doutrina e da jurisprudência no sentido de que é preciso reduzir a influência da forma, possibilitando, 
sempre que possível, o aproveitamento dos atos praticados, até porque - e isso precisa ser destacado em relação ao nosso momento processual - há uma corresponsabilidade na condução do feito.

Consideramos a palavra corresponsabilidade a que melhor retrata o movimento esperado da participação das partes no processo, em lugar da cooperação. Afinal, "Nada mais longe da realidade do que o ideal de cooperação entre as partes e o órgão judiciário. Entre as partes, reina a cizânia, cada qual buscando a satisfação do próprio interesse, e, não, a cooperação convergente reclamada imprópria e idealisticamente pelo art. $6^{\circ}$ (...)" (ARAKEM DE ASSIS, 2015, p. 1632).

Tudo a demonstrar que já não está mais apenas nos ombros do juiz zelar pela adequada tramitação do feito. As partes têm espaço para influir e não utilizar de tais possibilidades é abrir mão de um processo democrático, agora explicitamente reconhecido por lei, se era o que faltava mesmo frente à sua previsão na Constituição de 1988.

\section{Referências}

ARAGÃO, Egas Dirceu Moniz. Comentários ao código de processo civil. 10. ed. Rio de Janeiro: Forense, 2005.

ASSIS, Arakem de. Processo civil brasileiro. Vol. II. São Paulo: Revista dos Tribunais, 2015.

DIDIER Jr.; Fredie. Curso de direito processual civil. 17. ed. Revista, ampliada e atualizada. Salvador: Editora JusPODIVM, 2015, vol. 1.

DINAMARCO, Cândido Rangel. Instituições de Direito Processual Civil. Vol. II. 6. ed., revista e ampliada. São Paulo: Malheiros Editores, 2009.

FERRAJOLI, Luigi. Principia iuris. Teoría Del derecho y de la democracia. Vol. 2 Teoria de la democracia. Trad. de Perfecto Andre Ibañes, Carlos Bayon, Marina Gascón, Luis Prieto Sanchís y Alfonso Ruiz Miguel. Madrid: Editorial Trotta, 2011.

KELSEN, Hans. Teoria pura do direito. Tradução de MACHADO, João Batista. 6. ed. São Paulo: Martins Fontes, 1998.

LACERDA, Galeno. Despacho saneador. Porto Alegre: Livraria Sulina. 1953. 
PONTES DE MIRANDA, Francisco Cavalcanti. Comentários ao CPC.

Tomo III. 4. ed., revista e ampliada. Rio de Janeiro: Forense, 2001.

OLIVEIRA, Pedro Miranda de. O novíssimo sistema recursal conforme o CPC/2015. São Paulo: Conceito, 2015.

THEODORO JÚNIOR, Humberto. Curso de Direito Processual Civil. 56. ed. Rio de Janeiro: Forense, 2015.

Francisco José Rodrigues de Oliveira Neto - Doutor e Mestre em Direito pela Universidade Federal de Santa Catarina; Professor de Processo Civil do Curso de Graduação em Direito da UFSC; Professor do Curso de Mestrado e Doutorado em Direito da Universidade do Vale do Itajaí-SC e Desembargador do Tribunal de Justiça do Estado de Santa Catarina lotado na $2^{a}$ Câmara de Direito Público. 